\title{
The MAS NMR study of solid solutions based on the YAG crystal
}

\author{
Bohdan V. Padlyak, \\ Nikolaj A. Sergeev, \\ Marcin Olszewski, \\ Piotr Stępień
}

\begin{abstract}
An ${ }^{27} \mathrm{Al}$ magic angle spinning (MAS) nuclear magnetic resonance (NMR) study of nominally pure and $\mathrm{Cr}$-doped yttrium-aluminum garnet $\left(\mathrm{Y}_{3} \mathrm{Al}_{5} \mathrm{O}_{12}\right.$ and $\left.\mathrm{Y}_{3} \mathrm{Al}_{5} \mathrm{O}_{12}: \mathrm{Cr}\right)$ crystals is reported. It has been shown that the doping by $\mathrm{Cr}$ of the $\mathrm{Y}_{3} \mathrm{Al}_{5} \mathrm{O}_{12}$ crystals leads to the variation of the occupation by $\mathrm{Al}$ atoms both octahedrally and tetrahedrally coordinated sites of the garnet lattice.
\end{abstract}

Key words: ${ }^{27} \mathrm{Al}$ MAS NMR • local structure • solid solutions • yttrium-aluminum garnet (YAG)

B. V. Padlyak ${ }^{\bowtie}$

Division of Spectroscopy of Functional Materials, Institute of Physics,

University of Zielona Góra,

4a Szafrana Str., 65-516 Zielona Góra, Poland

and Spectroscopy Sector,

Institute of Physical Optics,

23 Dragomanov Str., 79-005 Lviv, Ukraine,

E-mail: B.Padlyak@if.uz.zgora.pl,bohdan@mail.lviv.ua

N. A. Sergeev, M. Olszewski, P. Stępień

Institute of Physics,

University of Szczecin,

15 Wielkopolska Str., 70-451 Szczecin, Poland

Received: 29 October 2014

Accepted: 30 January 2015

\section{Introduction}

The solid solutions based on the yttrium-aluminum garnet (YAG, chemical formula $-\mathrm{Y}_{3} \mathrm{Al}_{5} \mathrm{O}_{12}$ ), due to its unique optical, mechanical, and thermal properties, are widely used in modern technique as the most common materials for solid-state lasers and acousto-optical devices [1-3]. A YAG single crystal allows various isomorphic substitutions and extensive class of solid solutions whose properties substantially depend on the chemical composition and structural disordering or ordering in the distribution of atoms in the crystal lattice, caused by features of their synthesis and thermal treatment. In particular, the optical and luminescence properties of the Cr-doped $\mathrm{Y}_{3} \mathrm{Al}_{5} \mathrm{O}_{12}$ crystal $\left(\mathrm{Y}_{3} \mathrm{Al}_{5} \mathrm{O}_{12}\right.$ : $\mathrm{Cr}$ or YAG:Cr) can be essentially modified by substitutional occupation of the octahedral and tetrahedral sites by $\mathrm{Cr}$ ions in different valence states, generally $\mathrm{Cr}^{3+}$ and $\mathrm{Cr}^{4+}$ [4-7].

The single-crystalline solid solutions based on the YAG were intensively investigated during the last several decades by different methods, including optical spectroscopy as well as acoustic and heat pulse techniques [1-3]. One of the most informative methods for the study of the local structure of atoms in solid-state materials with a high sensitivity is a nuclear magnetic resonance (NMR). The YAG crystals were also investigated by the NMR technique [8-13]. Previous solid-state ${ }^{27} \mathrm{Al}$ NMR investigations of the YAG confirm that in the $\mathrm{Y}_{3} \mathrm{Al}_{5} \mathrm{O}_{12}$ crystals there are two different $\mathrm{Al}$ sites (octahedral and tetrahedral), whose difference in the ${ }^{27} \mathrm{Al}$ 
chemical-shift values enables the separation of the two contributions, which differ in the quadrupolar coupling constant $C_{Q}=e^{2} q Q / h$ [8-13]. According to NMR spectroscopy data, the $\mathrm{Al}^{3+}$ ions in the $\mathrm{Y}_{3} \mathrm{Al}_{5} \mathrm{O}_{12}$ crystal lattice occupy oxygen-coordinated tetrahedral (coordination number - 4) and octahedral (coordination number - 6) sites in the ratio: three tetrahedral sites, $N\left(\mathrm{Al}_{\mathrm{IV}}\right)$, to two octahedral sites, $N\left(\mathrm{Al}_{\mathrm{VI}}\right)$, that is, $\left(N\left(\mathrm{Al}_{\mathrm{IV}}\right): N\left(\mathrm{Al}_{\mathrm{VI}}\right)=3: 2\right)$.

The aim of this work was to study the effect of $\mathrm{Cr}^{3+}$ impurity on the occupation by the $\mathrm{Al}^{3+}$ ions of the tetrahedral and octahedral sites in the structure of the YAG crystal. The present paper reports a ${ }^{27} \mathrm{Al}$ magic angle spinning (MAS) NMR investigations of the nominally pure and Cr-doped YAG crystals. The preliminary results of these investigations have been published in [14].

\section{Experimental}

The nominally pure undoped $\left(\mathrm{Y}_{3} \mathrm{Al}_{5} \mathrm{O}_{12}\right)$ and Cr-doped $\left(\mathrm{Y}_{3} \mathrm{Al}_{5} \mathrm{O}_{12}: \mathrm{Cr}\right)$ single crystals of high optical quality and chemical purity were grown by standard Czochralski method along the [111] crystallographic direction in the $\left(\mathrm{N}_{2}+3 \% \mathrm{O}_{2}\right)$ atmosphere with a growth rate of $2 \mathrm{~mm}$ per hour [6]. The $\mathrm{Cr}$ impurity was added to the melt composition of as $\mathrm{Cr}_{2} \mathrm{O}_{3}$ oxide in amounts $1-5$ at.\%.

A 4-mm-diameter rotor was filled with a powdered (polycrystalline) sample obtained from single YAG crystals. The ${ }^{27} \mathrm{Al}$ MAS NMR spectra were registered at a frequency $104.26652 \mathrm{MHz}$, induction of static magnetic field $B=9.4 \mathrm{~T}$ using a Bruker Avance-400 NMR spectrometer, and spinning under magic angle with the frequency $14 \mathrm{kHz}$. The ${ }^{27} \mathrm{Al}$ nucleus (natural abundance $-100 \%$ ) has spin $I=$ $5 / 2$, and for the selective excitation of the central transition $(+1 / 2 \leftrightarrow-1 / 2)$, the optimal pulse duration will be equal to the duration of a nonselective $\pi / 2$ pulse divided by $(I+1 / 2)=3$ [15]. A free induction decay signals were recorded after the application of a single radiofrequency pulse. The recycle delay was $5 \mathrm{~s}$. A total of 100 acquisitions were sufficient to resolve the characteristic $\mathrm{Al}$ spectral features for the polycrystalline samples.

It should be noted that large differences in the quadrupolar coupling constants between tetragonal, $\mathrm{AlO}_{4}$ groups $\left(C_{Q}=e^{2} q Q / h\right.$ typically about $\left.6 \mathrm{MHz}\right)$, and octahedral, $\mathrm{AlO}_{6}$ groups (typically $C_{Q}<0.6$ $\mathrm{MHz}$ ), lead to large differences in the linewidth and lineshape of the MAS NMR signals $[10,16,17]$. Due to large second-order quadrupolar broadening, the ${ }^{27} \mathrm{Al}$ to a greater extent, the NMR lineshapes are very broad and require special acquisition conditions to obtain understandable spectra. When the quadrupolar coupling constant $C_{Q}>10 \mathrm{MHz}$, it becomes impossible to acquire the whole spectrum at once in the acquisition linewidth [15]. The analysis of the quantitative accuracy in quadrupolar MAS NMR spectroscopy has been performed in [10]. The fractions of octahedrally and tetrahedrally coordinated $\mathrm{Al}$ sites, $N\left(\mathrm{Al}_{\mathrm{VI}}\right)$ and $N\left(\mathrm{Al}_{\text {IV }}\right)$, were determined using the method proposed by P. J. Bray [18].
From our analysis, we realize that the lineshape of ${ }^{27} \mathrm{Al}$ NMR MAS spectra depends on the pulse duration, and only from ${ }^{27} \mathrm{Al}$ NMR MAS spectrum obtained with pulse duration $0.7 \mu \mathrm{s}$, it follows the relation 2:3 for the population of octahedrally and tetrahedrally coordinated $\mathrm{Al}$ sites $\left(N\left(\mathrm{Al}_{\mathrm{VI}}\right)\right.$ and $N\left(\mathrm{Al}_{\text {IV }}\right)$ ) for the undoped YAG crystals [14]. So, the ${ }^{27} \mathrm{Al}$ NMR MAS spectra of YAG with a touch of $\mathrm{Cr}^{3+}$ ions were obtained by single-pulse experiments with a pulse duration of $0.7 \mu \mathrm{s}$. It should be noted that the pulse duration of $0.7 \mu$ s is close to duration $\pi / 6$.

The Dmfit program $[19,20]$ was used to simulate the ${ }^{27} \mathrm{Al}$ MAS NMR spectra and to extract the isotropic chemical shifts $\left(\delta_{\text {iso }}\right)$, quadrupolar coupling constants $\left(C_{Q}\right)$, and the asymmetry parameters $(\eta)$.

\section{Results and discussion}

Figures 1 and 2 present the ${ }^{27} \mathrm{Al}$ MAS NMR spectra obtained for powdered crystalline samples $\mathrm{Y}_{3} \mathrm{Al}_{5} \mathrm{O}_{12}$ and $\mathrm{Y}_{3} \mathrm{Al}_{5} \mathrm{O}_{12}$ :Cr. All ${ }^{27} \mathrm{Al}$ MAS NMR spectra, which

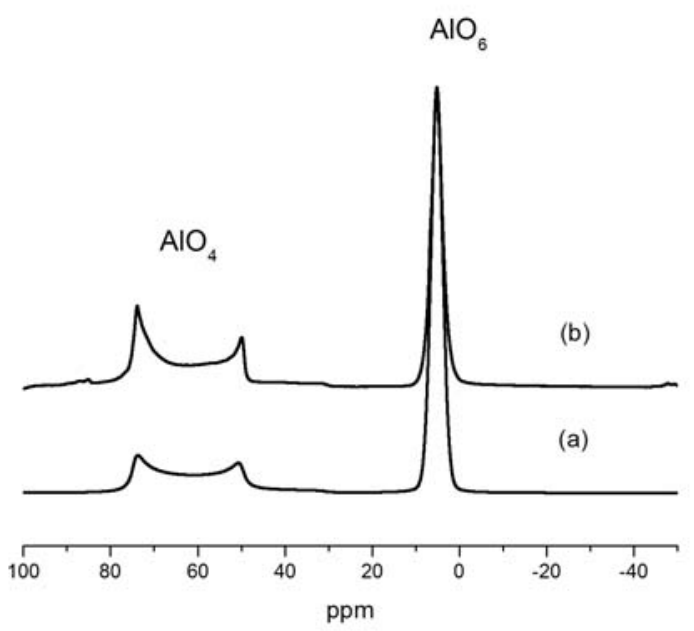

Fig. 1. The theoretical (curve 'a') and experimental (curve 'b') ${ }^{27} \mathrm{Al}$ MAS NMR spectra of the polycrystalline nominally pure $\mathrm{YAG}\left(\mathrm{Y}_{3} \mathrm{Al}_{5} \mathrm{O}_{12}\right)$.

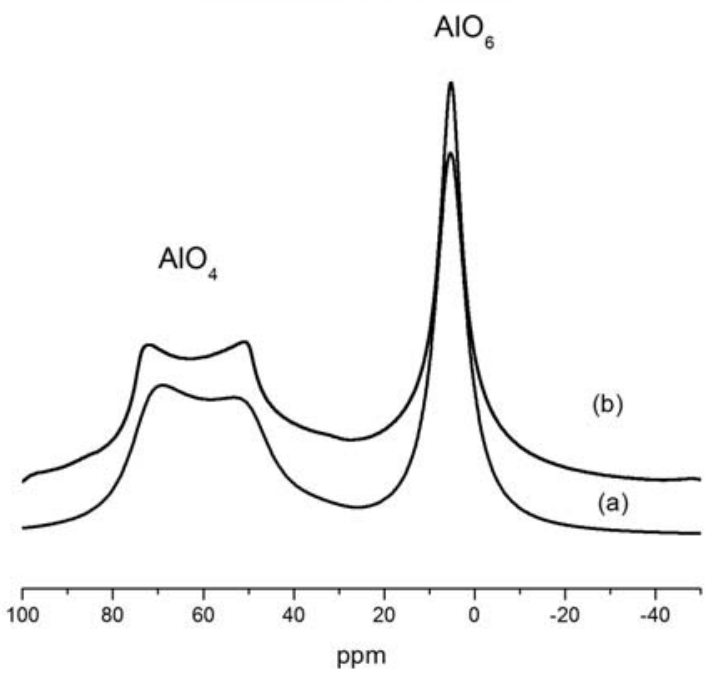

Fig. 2. The theoretical (curve 'a') and experimental (curve 'b') ${ }^{27} \mathrm{Al}$ MAS NMR spectra of the polycrystalline $\mathrm{Cr}$-doped YAG $\left(\mathrm{Y}_{3} \mathrm{Al}_{5} \mathrm{O}_{12}: \mathrm{Cr}\right)$. 
are observed in YAG, contain two peaks corresponding to the tetragonal $\left(\mathrm{AlO}_{4}\right)$ and octahedral $\left(\mathrm{AlO}_{6}\right)$ structural atomic groups [10].

In contrast to nuclei with spin $1 / 2$, the quadrupolar nucleus ${ }^{27} \mathrm{Al}$ with spin 5/2 has several NMR transitions, which depend not only on magnetic interactions but also on the interaction between nuclear electric quadrupole moment $Q$ and the electric field gradient created by the surroundings [15]. The effect of the quadrupolar interaction is always assumed to be small with respect to the Zeeman interaction and is therefore deduced from a perturbation calculation. To first order, the quadrupole interaction has no effect on the central transition $\left( \pm 1 / 2 \mp^{1 / 2}\right)$. Only the satellite transitions $( \pm 1 / 2 \leftrightarrow \pm 3 / 2 ; \pm 3 / 2 \leftrightarrow \pm 5 / 2)$ are affected, and for these the first-order, quadrupolar effect is of the order of $v_{\mathrm{Q}}=3 C_{Q} / 2 I(2 I-1)$ [15]. The central $\left( \pm \frac{1}{2} \mp 1 / 2\right)$ transition is affected by quadrupolar interaction to second order, and the second-order quadrupolar term is typically from $10^{2}$ to $10^{3}$ smaller than the $v_{Q}$. As a consequence, the central transition yields a narrower and more intense line in the NMR spectrum. As the MAS NMR experiment has no 'magical' properties on the second order quadrupolar interaction, MAS will not average this interaction, and usually, it is observed only as a powder pattern for this central transition [15].

In MAS NMR spectroscopy, the second-order quadrupolar shift of the central transition $( \pm 1 / 2 \leftrightarrow$ $\bar{\mp}^{1 / 2}$ ) for nucleus with spin $I=5 / 2$ is given according to [15] by the following relation:

(1) $v\left(v_{L}, v_{Q}, \eta, \alpha, \beta\right)=\frac{v_{Q}^{2}}{v_{L}}\left(-\frac{4}{15}\left[1+\frac{\eta^{2}}{3}\right]+\frac{1}{36} g(\alpha, \beta)\right)$ where $v_{\mathrm{L}}$ is the Larmor frequency of the ${ }^{27} \mathrm{Al}$ nuclei;

$$
v_{Q}=\frac{3 e Q}{20 h} V_{\mathrm{ZZ}} \text { and } \eta=\frac{V_{\mathrm{XX}}-V_{\mathrm{YY}}}{V_{\mathrm{ZZ}}}
$$

where $\left|V_{\mathrm{XX}}\right| \leq\left|V_{\mathrm{YY}}\right| \leq\left|V_{\mathrm{ZZ}}\right| \equiv|e q|$ are the eigenvalues of the traceless tensor of the electric field gradient (EFG);

$$
\begin{gathered}
g(\alpha, \beta)=7\left(9-6 \cos 2 \alpha-7 \eta^{2} \cos ^{2} 2 \alpha\right) \cos ^{4} \beta \\
-\left(54+4 \eta^{2}-48 \eta \cos 2 \alpha+14 \eta^{2} \cos ^{2} 2 \alpha\right) \cos ^{2} \beta \\
+\left(15-6 \eta \cos 2 \alpha+7 \eta^{2} \cos ^{2} 2 \alpha\right)
\end{gathered}
$$

where $\eta=\left(V_{\mathrm{XX}}-V_{\mathrm{YY}}\right) / V_{\mathrm{ZZ}}$ is the asymmetry parameter of the EFG tensor, $\alpha$ and $\beta$ are the Euler angles, which define the principal axis system of the EFG tensor.

The NMR signal for a single nucleus can be formally represented, neglecting any residual linewidth, by a Dirac delta function:

$$
f\left(v, v_{L}, v_{Q}, \eta, \alpha, \beta\right) \sim \delta\left(v-v\left(v_{L}, v_{Q}, \eta, \alpha, \beta\right)\right)
$$

Table 1. Quadrupolar coupling constants $\left(C_{Q}\right)$, isotropic chemical shifts $\left(\delta_{\text {iso }}\right)$, and the broadening parameters $\left(\Delta v_{\mathrm{L}}\right)$ of the Lorentzian function, $p\left(v_{\mathrm{Q}}, \eta\right)$, for $\mathrm{Al}_{\mathrm{VI}}$ and $\mathrm{Al}_{\mathrm{IV}}$ in the undoped and Cr-doped YAG crystals $\eta=0$

\begin{tabular}{lcccccc}
\hline \multirow{2}{*}{$\begin{array}{c}\text { Al sites } \\
\text { in YAG crystal }\end{array}$} & \multicolumn{3}{c}{ Undoped YAG } & \multicolumn{3}{c}{ Cr-doped YAG } \\
\cline { 2 - 7 } & $C_{Q}[\mathrm{MHz}]$ & $\delta_{\text {iso }}[\mathrm{ppm}]$ & $\Delta v_{\mathrm{L}}[\mathrm{kHz}]$ & $C_{Q}[\mathrm{MHz}]$ & $\delta_{\text {iso }}[\mathrm{ppm}]$ & $\Delta v_{\mathrm{L}}[\mathrm{kHz}]$ \\
\hline Tetrahedral & 6.1 & 82 & 0.15 & 6.07 & 80.26 & 0.54 \\
Octahedral & 0.6 & 5.38 & 0.9 & 0.607 & 5.31 & 0.9 \\
\hline
\end{tabular}

For a randomly oriented powder of a disorder sample, due to the residual linewidth and to the large number of the randomly distributed environments, the formal expression of the full NMR spectrum can be written as follows:

$$
\begin{aligned}
F(v) & \sim \int_{-\infty}^{\infty} d v_{Q} \int_{0}^{1} p\left(v_{Q}, \eta\right) \\
& \cdot\left\{\frac{1}{4 \pi} \int_{0}^{2 \pi} \int_{0}^{\pi} \delta\left(v-v\left(v_{\mathrm{L}}, v_{Q}, \eta, \alpha, \beta\right)\right)\right\} d \eta
\end{aligned}
$$

where $p\left(v_{Q}, \eta\right)$ is the weighted average function, which describes the distribution of the quadrupolar parameters $v_{Q}$ and $\eta$.

From formula (5), it follows that the spectrum results from two successive integrations. The first integration, over all possible orientations of the EFG, is the well-known powder spectrum averaged for given values of the quadrupolar parameters $v_{Q}$ and $\eta$. The second integration is the weighted average of the powder lineshapes over all possible quadrupolar parameters $v_{Q}$ and $\eta$. The distribution of quadrupolar parameters is described by the function $p\left(v_{Q}, \eta\right)$ and various approaches to choice of this function have been discussed in $[19,20]$. In this work, we used the Dmfit model of MAS NMR spectrum and the Lorentzian or Gaussian curves with the broadening of slightly distinct environment of nuclei [19].

The isotropic chemical shifts $\left(\delta_{\text {iso }}\right)$, quadrupolar coupling constants $\left(C_{Q}\right)$ of the ${ }^{27} \mathrm{Al}$ nuclei in the $\mathrm{AlO}_{4}$ and $\mathrm{AlO}_{6}$ groups obtained by Dmfit program [19] are represented in Table 1.

The YAG $\left(\mathrm{Y}_{3} \mathrm{Al}_{5} \mathrm{O}_{12}\right)$ crystal has a body-centered cubic structure, space group $\operatorname{Ia} 3 d\left(\mathrm{O}_{h}^{10}\right)[21,22]$. One unit cell of the garnet contains 40 aluminum ions, of which 16 are octahedrally ( $a$ site) and 24 are tetrahedrally coordinated ( $d$ site) by oxygen ions. The oxygen-coordinated octahedral and tetrahedral sites are distorted so that the crystal field at the aluminum ions is axially symmetric with the axes directed along the cubic axes $a, b, c$ ( $d$ sites) and along the cube body diagonals ( $a$ sites). There are two structurally nonequivalent positions of aluminum atoms in the YAG crystal structure: the Al occupies 16 octahedral positions and 24 tetrahedral positions and this is in a good agreement with NMR data, that is, $N\left(\mathrm{Al}_{\mathrm{VI}}\right): N\left(\mathrm{Al}_{\mathrm{IV}}\right) \cong$ $2: 3$ [10]. In the YAG crystal, the point symmetry of tetrahedral $\left(\mathrm{AlO}_{4}\right)$ structural groups are $S_{4}$ [21]. The presence of an electric quadrupole moment means that the ${ }^{27} \mathrm{Al}$ nucleus will interact strongly with the local electric field surrounding of the nucleus. This interaction has a significant effect on the observed NMR spectrum. The strength of local electric field gradient is described by a second rank tensor with parameters $\Delta v_{\mathrm{L}}$ or $\Delta v_{\mathrm{G}}$, which indicate a distribution 
principal axis elements $V_{i i}(i=\mathrm{X}, \mathrm{Y}, \mathrm{Z})$ [15]. The symmetry of the EFG manifests predictable and large effects in the spectral line shape of the ${ }^{27} \mathrm{Al}$ species in the solid state and is quantified by the asymmetry parameter $\left.\left(\eta=\left(V_{\mathrm{XX}}-V_{\mathrm{YY}}\right) / V_{\mathrm{ZZ}}\right)\right)$. In the case of the axially symmetric EFG tensor around the quadrupo$\operatorname{lar}\left(V_{\mathrm{XX}}=V_{\mathrm{YY}}\right)$ and $\eta=0$ [15]. The ${ }^{27} \mathrm{Al}$ MAS NMR spectra of the tetrahedral aluminum site in the nominally pure undoped YAG $\left(\mathrm{Y}_{3} \mathrm{Al}_{5} \mathrm{O}_{12}\right)$ and $\mathrm{Cr}$-doped YAG $\left(\mathrm{Y}_{3} \mathrm{Al}_{5} \mathrm{O}_{12}\right.$ : $\left.\mathrm{Cr}\right)$ are presented in Figs. 1 and 2, revealing the characteristic two-peak MAS quadrupolar powder pattern for an axially symmetric EFG tensor [15]. This single site is adequately fit with $\eta$ equals to 0 , a quadrupolar coupling parameter, $C_{Q}$, set to $6.1 \mathrm{MHz}$ (Table 1). The value of a quadrupolar coupling parameter gives the important information about the different types of the aluminum coordination in a crystal lattice. The four-coordinated aluminum possesses a quadrupolar coupling constant, $C_{Q}$, that equals about $6 \mathrm{MHz}[15]$.

In the YAG lattice, the point symmetry of octahedral $\left(\mathrm{AlO}_{6}\right)$ groups is $C_{3 i}$, and so, the environment of $\mathrm{Al}$ atom has a very symmetric but slightly distorted octahedron $[21,22]$. Due to the axial symmetry of the slightly distorted octahedral aluminum position, the EFG tensor is characterized by only one $\left(V_{\mathrm{zz}}\right)$ component and $C_{Q}=0.6 \mathrm{MHz}$ (Table 1$)$. The asymmetry parameter is $\eta=0$ for $\mathrm{AlO}_{6}$ groups in the garnet lattice. This result is confirmed experimentally (Table 1). So a symmetric peak at about $5.38 \mathrm{ppm}$ in the ${ }^{27} \mathrm{Al}$ MAS NMR spectrum is attributed to the $\mathrm{AlO}_{6}$ groups, and an asymmetric broad peak at about $82 \mathrm{ppm}$ is assigned to the $\mathrm{AlO}_{4}$ groups. The different frequency positions of the MAS NMR signals of the aluminum-oxygen bonding groups are connected with different ${ }^{27} \mathrm{Al}$ isotropic chemical shifts of the $\mathrm{AlO}_{4}$ and $\mathrm{AlO}_{6}$ groups [10]. The line at $50-70 \mathrm{ppm}$ is a line of group $\mathrm{AlO}_{4}$ for powder sample. The reason for observable asymmetry of the experimental lines at 50-70 ppm in pure and the Cr-doped samples, in our opinion, is connected with variations of quadrupole coupling constants $\left(C_{Q}\right)$ and the broadening parameters $\left(\Delta v_{\mathrm{L}}\right)$ of the Lorentzian function, $p\left(v_{Q}, \eta\right)$.

From Fig. 2, we can see that the YAG is activated with $\mathrm{Cr}^{3+}$ ions, the quadrupolar coupling constant coincides within the limits of an experimental error with $C_{Q}$ in the nominally pure $\mathrm{Y}_{3} \mathrm{Al}_{5} \mathrm{O}_{12}$. However, the lines of ${ }^{27} \mathrm{Al}$ MAS NMR spectrum in $\mathrm{Y}_{3} \mathrm{Al}_{5} \mathrm{O}_{12}$ : $\mathrm{Cr}$ are broadened in comparison with NMR lines in the nominally pure YAG. These broadening of NMR lineshapes of the ${ }^{27} \mathrm{Al}$ nuclei can be related with the change of local EFG at the sites of $\mathrm{Al}$ nuclei that results in the interaction of the $\mathrm{Cr}^{3+}$ paramagnetic ions with magnetic moment of the ${ }^{27} \mathrm{Al}$ nuclei [17]. The calculations of the electronic structure and the electric field gradient tensor in YAG [16] have shown that the EFG tensor at the $\mathrm{Al}$ atom sites is well described by taking into account the nearest-neighbors only. Therefore, the paramagnetic shift from the $\mathrm{Cr}^{3+}$ paramagnetic ions gives the main contribution to the broadening of ${ }^{27} \mathrm{Al}$ NMR lineshapes at the octahedral and tetrahedral aluminum sites in $\mathrm{Y}_{3} \mathrm{Al}_{5} \mathrm{O}_{12}$ : $\mathrm{Cr}$ crystals.

If some part of the $\mathrm{Y}^{3+}$ ions is replaced by $\mathrm{Cr}^{3+}$ paramagnetic ions, the Larmor frequencies of ${ }^{27} \mathrm{Al}$ nuclei undergo a paramagnetic shift, which depends on the number of paramagnetic $\mathrm{Cr}^{3+}$ ions in the nearest-neighbor environment of aluminum ions. The paramagnetic shift according to [17] can be determined from the relation:

$$
\Delta v_{P}=\gamma \sum_{i} \frac{\left\langle\mu_{i}\right\rangle\left(1-3 \cos ^{2} \vartheta_{i}\right)}{R_{i}^{3}}
$$

where $\gamma$ is the gyromagnetic ratio of ${ }^{27} \mathrm{Al}$ nucleus, $<\mu_{i}>$ is the average magnetic moment of $\mathrm{Cr}^{3+}$ ions surrounding ${ }^{27} \mathrm{Al}$ nucleus, $R_{i}$ is the distance between a ${ }^{27} \mathrm{Al}$ nucleus, and the $i$-th $\mathrm{Cr}^{3+}$ ion, $\theta_{i}$ is the angle between vectors $\boldsymbol{R}_{i}$ and external magnetic field $\boldsymbol{B}_{0}$.

At room temperature, the average dipole moment of $\mathrm{Cr}^{3+}$ can be calculated using relation:

$$
\left\langle\mu_{i}\right\rangle=\frac{\mu_{\mathrm{B}}^{2} g^{2} J(J+1) B_{0}}{3 k T}
$$

where $g$ is the Lande factor, $\mu_{\mathrm{B}}$ is the Bohr magneton, $J$ is the total angular momentum of the $\mathrm{Cr}^{3+}$ ion.

In the $\mathrm{Y}_{3} \mathrm{Al}_{5} \mathrm{O}_{12}: \mathrm{Cr}$ crystal, there exists a certain probability of finding different number $(m)$ of the $\mathrm{Cr}^{3+}$ ions in the nearest-neighbor environment of an $\mathrm{Al}^{3+}$ cation. For a fully disordered solid solution, this probability is given by the binominal distribution:

$$
p(x, m)=\frac{n !}{(n-m) !} \frac{x^{m}(1-x)^{n-m}}{m !}
$$

where $n$ is the total number of positions occupied by $\mathrm{Y}^{3+}$ and $\mathrm{Cr}^{3+}$ ions in the nearest-neighbor environment of $\mathrm{Al}^{3+}$.

In some mixed crystals, for example, in the $\mathrm{Y}_{1-x} \mathrm{Er}_{x} \mathrm{AlO}_{3}(0<x<0.45)$, there are the substitutional ordering due to the mutual arrangement of the $\mathrm{Y}^{3+}$ and $\mathrm{Er}^{3+}$ ions in the lattice sites [23]. Partial ordering in the substitution of $\mathrm{Er}^{3+}$ ions on $\mathrm{Y}^{3+}$ may change considerably the probability of distribution in the local environment of an $\mathrm{Al}$ ion [23]. The problem of the partial ordering of the $\mathrm{Me}^{3+}$ impurity ions in mixed garnets $\mathrm{Y}_{3} \mathrm{Al}_{5} \mathrm{O}_{12}: \mathrm{Me}^{3+}$ was investigated by NMR method in [17]. In particular, it was shown that in the $\mathrm{Y}_{3-x} \mathrm{Dy}_{x} \mathrm{Al}_{5} \mathrm{O}_{12}$ there is no substitutional ordering [12].

The areas under the curves of the ${ }^{27} \mathrm{Al}$ NMR lines at the octahedral and tetrahedral aluminum sites are proportional up to the quantity of the ${ }^{27} \mathrm{Al}$ nuclei in these groups. The simulation of the experimental ${ }^{27} \mathrm{Al}$ MAS NMR spectrum of the $\mathrm{Y}_{3} \mathrm{Al}_{5} \mathrm{O}_{12}: \mathrm{Cr}$ (Fig. 2b) gives the fractions of the $\mathrm{AlO}_{6}$ and $\mathrm{AlO}_{4}$ groups: $N\left(\mathrm{Al}_{\mathrm{VI}}\right) / N\left(\mathrm{Al}_{\mathrm{IV}}\right) \cong 0.85$. So the doping by $\mathrm{Cr}$ of the $\mathrm{Y}_{3} \mathrm{Al}_{5} \mathrm{O}_{12}$ crystals leads to the variation of the occupation by Al atoms both octahedrally and tetrahedrally coordinated sites of the garnet lattice.

\section{Conclusions}

The ${ }^{27} \mathrm{Al}$ MAS NMR spectroscopy of the undoped YAG crystals clearly shows the relation $2: 3$ for occupation of the octahedrally and tetrahedrally coordinated $\mathrm{Al}$ sites, respectively. This result coincides with corresponding structural reference data for YAG crystals. The ${ }^{27} \mathrm{Al}$ MAS NMR spectroscopy also shows that the doping of YAG crystals by $\mathrm{Cr}$ leads to 
the variation of the occupation by $\mathrm{Al}$ atoms both octahedral and tetrahedral cationic sites of the garnet lattice. The obtained results confirm the statistical distribution of $\mathrm{Cr}$ ions for both octahedral $\left(\mathrm{AlO}_{6}\right)$ and tetrahedral $\left(\mathrm{AlO}_{4}\right)$ positions. Finally, it should be noted that the MAS NMR spectroscopy is a very sensitive and powerful method for investigating the local structure of main structural units in ordered and disordered solids and the redistribution of atoms between different sites caused by doping impurities.

Acknowledgments. This work was supported by the University of Zielona Góra (Poland) and Szczecin University (Poland).

\section{References}

1. Powell, R. C. (1998). Physics of solid state laser materials. New York: Springer-Verlag.

2. Cheng, Li, Jie, Song, Deyuan, Shen, Yuhui, Cao, Nam Seong, Kim, \& Ken-ichi, Ueda. (2000). Flash-lamppumped acousto-optic Q-switched Cr-Tm:YAG laser. Optical Rev., 7(1), 58-61.

3. Kalisky, Y. (2006). The physics and engineering of solid state lasers. SPIE Digital Library, ebooks. DOI: 10.1117/3.660249.

4. Hehir, J. P., Henry, M. O., Larkin, J. P., \& Imbusch, G. F. (1974). Nature of the luminescence from YAG: $\mathrm{Cr}^{3+}$. J. Phys. C-Solid State Phys., 7(12), 2241.

5. Henderson, B., Gallagher, H. G., Han, T. P. J., \& Scott, M. A. (2000) Optical spectroscopy and optimal crystal growth of some $\mathrm{Cr}^{4+}$ doped garnets. J. Phys.-Condens. Matter, 12, 1927-1938.

6. Ubizskii, S. B., Melnyk, S. S., Padlyak, B. V., Matkovskii, A. O., Jankowska-Frydel, A., \& Frukacz, Z. (2001) Chromium recharging processes in the $\mathrm{Y}_{3} \mathrm{~A}_{5} \mathrm{O}_{12}: \mathrm{Mg}, \mathrm{Cr}$ single crystal under the reducing and oxidizing annealing influence. Proc. SPIE, 4412, 63.

7. Ubizskii, S. B., Matkovskii, A. O., Syvorotka, I. M., Melnyk, S. S., Kopczynski, K., Mierczyk, Z., \& Frukacz, Z. (1999). Growth and characterization of YAG: $\mathrm{Cr}^{4+}$ epitaxial films. Proc. SPIE, 3724, 353.

8. Brog, K. C., Jones, W. H., \& Verber, C. M. (1966). ${ }^{27} \mathrm{Al}$ and ${ }^{89} \mathrm{Y}$ nuclear magnetic resonance in yttrium-aluminum garnet. Phys. Lett., 20, 258-260.

9. Grimminck, D. L. A. G., Polman, B. J. W., Arno, P. M., Kentgens, A. P. M., \& Meerts, W. L. (2011). EASY-GOING deconvolution: Combining accurate simulation and evolutionary algorithms for fast deconvolution of solid-state quadrupolar NMR spectra. J. Magn. Reson., 211, 114-120. DOI: 10.1016/j. jmr.2011.04.009.

10. Massiot, D., Bessada, C., Coutures, J. P., \& Taulelle, F. (1990). A quantitative study of ${ }^{27} \mathrm{Al}$ MAS NMR in crystalline YAG. J. Magn. Reson., 90, 231-242.
11. Dupree, R., Lewis, M. H., \& Smith, M. E. (1988). Structural characterization of ceramic phases with high-resolution ${ }^{27} \mathrm{Al}$ NMR. J. Appl. Crystallogr., 27, 109-116. DOI: 10.1107/S0021889887010069.

12. Vosegaard, T., Byriel, I. P., Pawlak, D. A., Wozniak, K., \& Jakobsen, H. J. (1998). Crystal structure studies on the garnet $\mathrm{Y}_{3} \mathrm{Al}_{5} \mathrm{O}_{12}$ by ${ }^{27} \mathrm{Al}$ single-crystal NMR spectroscopy. J. Am. Chem. Soc., 120, 7900-7904.

13. Florian, P., Gervais, M., Douy, A., Massiot, D., \& Coutures, J. P. (2001). A multi-nuclear multiple-field nuclear magnetic resonance study of the $\mathrm{Y} 2 \mathrm{O} 3-\mathrm{Al} 2 \mathrm{O} 3$ phase diagram. J. Phys. Chem. B, 105, 379-391. DOI: 10.1021/jp0008851.

14. Padlyak, B. V., Sergeev, N. A., \& Olszewski, M. (2014). The ${ }^{27} \mathrm{Al}$ MAS NMR study of the $\mathrm{Y}_{3} \mathrm{Al}_{5} \mathrm{O}_{12}$ and $\mathrm{Y}_{3} \mathrm{Al}_{5} \mathrm{O}_{12}$ :Cr garnets. In III Forum Polskiej Grupy EMR/EPR, 23-25 czerwca 2014 (pp. 145-148). Kraków, Poland.

15. Freude, D. (2000). Quadrupolar nuclei in solid-state nuclear magnetic resonance. In R. A. Meyers (Ed.), Encyclopedia of analytical chemistry (pp. 12188-12224). Chichester: John Wiley \& Sons Ltd.

16. Kasperovich, V. S., Sodel', N. E., \& Shelyapina, M. G. (2006). Nonempirical cluster calculation of the electric field gradient tensor in yttrium-aluminium garnet $\mathrm{Y}_{3} \mathrm{Al}_{5} \mathrm{O}_{12}$. Phys. Solid State, 48(9), 1684-1688. DOI: 10.1134/S1063783406090101.

17. Vorob'ev, A. A., Grigor'eva, N. A., Ivanov, S. N., Kasperovich, V. S., Khazanov, E. N., \& Charnaya, E. V. (1998). Quadrupole and paramagnetic interaction of ${ }^{27} \mathrm{Al}$ nuclei in mixed yttrium-dysprosium aluminium garnets $\mathrm{Y}_{3-\mathrm{x}} \mathrm{Dy}_{\mathrm{x}} \mathrm{Al}_{5} \mathrm{O}_{12}$. Phys. Solid State, 40(6), 956-959.

18. Bray, P. J. (1999). NMR and NQR studies of boron in vitreous and crystalline borates. Inorg. Chim. Acta, 289, 158-173.

19. Massiot, D., Fayon, F., Capron, M., King, I., Le Calve, S., Alonso, B., Durand, J. -O., Bujoli, B., Gan, Z., \& Hoatson, G. (2002). Modelling one- and two-dimensional solid-state NMR spectra. Magn. Reson. Chem., 40, 70-76.

20. d'Espinose de Lacaillerie, J. -B., Fretigny, Ch., \& Massiot, D. (2008). MAS NMR spectra of quadrupolar nuclei in disordered solids: The Czjzek model. J. Magn. Reson., 192, 244-251. DOI: 10.1016/j. jmr.2008.03.001.

21. Menzer, G. (1928). Die kristallstruktur der granate. Z. Kristallographie, 69, 300-396.

22. Geller, S. (1967). Crystal chemistry of the garnets. $Z$. Kristallographie, 125, 1-47.

23. Charnaya, E. V., Grigoreva, N. A., Ivanov, S. N., Kasperovich, V. S., Khazanov, E. N., \& Taranov, A. V. (1995). Structure and ordering of mixed aluminates $\mathrm{Y}_{1-x} \mathrm{Er}_{x} \mathrm{AlO}_{3}$ by NMR, acoustic, and heat pulse techniques. Phys. Status Solidi A-Appl. Mat., 147(2), 313-324. DOI: 10.1002/pssa.2211470203. 